\title{
Rabies after solid organ transplantation
}

\section{Background and epidemiology:}

The US Centers for Disease Control and Prevention has confirmed that rabies was the cause of death in 3 transplant organ recipients (liver and kidneys) in whom encephalitis developed 3-4 weeks after transplantation. Their common donor had died of extensive subarachnoid bleeding of unknown cause. According to eligibility screening and testing, he had had no contraindications to transplantation, although a public health investigation later revealed that he had reported being bitten by a bat. ${ }^{1}$

Rabies is an acute infection of the central nervous system caused by neurotropic lyssaviruses that are transmitted in the saliva of infected mammals. The disease usually develops after a bite by an infected animal in developed countries, most often a bat. ${ }^{1}$ Patients frequently have no recollection of being bitten by a bat, although they may have noticed one in or near their dwelling or workplace. ${ }^{2}$

Rabies transmission as a result of transplantation has been described among recipients of transplanted corneas (8 cases in 5 countries $^{3}$ ), but never before among solid organ transplant recipients. In the 3 recipients described above, infection most likely occurred via neuronal tissue within the transplanted liver and kidneys.

Human rabies in Canada is rare: only 22 deaths from rabies have been reported in the last 80 years. Between 1000 and 1500 Canadians receive postexposure prophylaxis for rabies each year. ${ }^{2}$ The rate of organ dona$\therefore$ tion in Canada is only 14 per million population (or around 440 per year), which is much lower than in Spain or the United States (31.5 and 22.7 per million, respectively). ${ }^{4}$ Each year, about 4000 Canadians wait for an organ transplant.

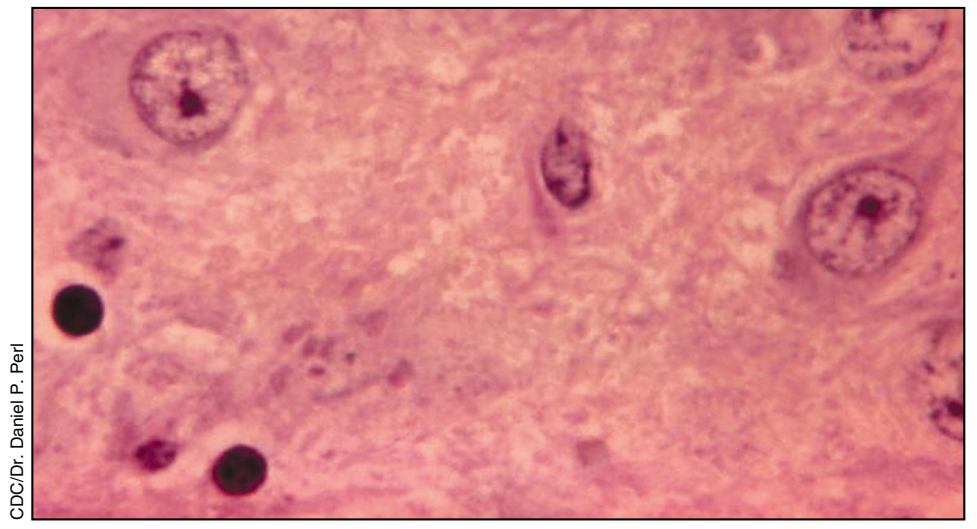

Fig. 1: Micrograph showing histopathologic changes associated with rabies encephalitis. The pathognomonic Negri bodies are cellular inclusions found most frequently in the pyramidal cells of Ammon's horn and the Purkinje cells of the cerebellum.

Clinical management: According to Canadian transplantation standards, donors are approved after passing thorough physical and psychosocial assessments by a specialized health care team at 1 of the 28 hospitals in Canada that perform organ transplantation. ${ }^{5} \mathrm{~A}$ series of serological tests are done, including screening for HIV, hepatitis B, human T-lymphotropic virus types 1 and 2, cytomegalovirus, Epstein-Barr virus and syphilis. Donors are not tested for rabies, since the disease is rare, but on a compulsory questionnaire they or their relatives are asked whether the donor has been bitten by a bat. If rabies is suspected, a diagnosis can be made by serologic tests and confirmed by direct brain biopsy (see Fig. 1).

As for potential recipients, a sharing agreement exists across Canada that the donated organ goes to the person on the waiting list who needs it most. This decision also depends on the blood groups of the donor and the recipient, which should be identical or compatible; the size of the organ transplanted; and the tissue match for kidney patients. $^{5}$

Prevention: Donor tissues are tested to meet minimum pro- curement standards, the aim being to decrease the risk of transmitting an infection without decreasing the number of organs for transplantation. Prudence dictates that organ donors with rabies-compatible illnesses should be evaluated for rabies before transplantation, since a clinical history of infection by contact with wild animals, especially bats, is unreliable.

\section{Aleksandra Mišak \\ Editorial Fellow \\ $C M A J$}

\section{References}

1. Investigation of rabies infections in organ donor and transplant recipients Alabama, Arkansas, Oklahoma, and Texas, 2004. MMWR Morb Mortal Wkly Rep 2004;53:586-9. Available: www .cdc.gov/mmwr/preview/mmwrhtml /mm5326a6.htm (accessed 2004 July 15).

2. Weir E. Putting the bite on rabies. CMAJ 2002;167(7):781.

3. Human rabies prevention - United States, 1999: recommendation of the Immunization Practices Advisory Committee (ACIP). MMWR Morb Mortal Wkly Rep 1999;44 (no RR-1).

4. Baxter D, Smerdon J. Donation matters: demographics and organ transplants in Canada, 2000 to 2040. Report no 46. Vancouver: The Urban Futures Institute; 2000. Available: www.urbanfutures .com/Institute/abstracts/report46.htm (accessed 2004 July 15).

5. Health Canada. Organ and tissue information site. Ottawa: Health $\mathrm{Ca}-$ nada; 2002. Available: www.hc-sc gc.ca/english/organandtissue/ (accessed 2004 July 15). 